Gut, 1985, 26, 8-13

\title{
Hepatic cirrhosis in young adults: association with adolescent onset of alcohol and parenteral heroin abuse
}

\author{
D M NOVICK, R W ENLOW, A M GELB, R J STENGER, M FOTINO, \\ J W WINTER, S R YANCOVITZ, M D SCHOENBERG, AND M J KREEK \\ From the Departments of Medicine and Pathology, Beth Israel Medical Center, and The Mount Sinai School \\ of Medicine of the City University of New York; The Department of Rheumatic Diseases, Hospital for Joint \\ Diseases Orthopaedic Institute; The New York Blood Center, and The Rockefeller University, New York, \\ New York; USA
}

SUMmaRY Hepatic cirrhosis is infrequently diagnosed in young adults. In a hospital for addictive diseases in New York City, we found cirrhosis in 53 patients under age 35 within just 40 months. The cirrhosis was biopsy-proven in 37 patients (group I) and diagnosed clinically in 16 patients with severe liver disease (group II). Alcohol abuse was found in 51 patients (96\%), and parenteral heroin abuse was seen in $52(98 \%)$. The duration of alcohol abuse was seven or fewer years in 24 patients $(45 \%)$ and 10 or fewer in $39(74 \%)$. In $44(83 \%)$, the substance abuse began in adolescence. Comparison of group I cirrhotic patients with 65 non-cirrhotic biopsied patients showed that cirrhosis was significantly associated with abuse of both alcohol and parenteral heroin $(\mathrm{p}<0.001)$. The distribution of 66 HLA antigens from A, B, C, and DR loci showed no differences when 42 patients were compared with 42 ethnically-matched control substance abusers. The early development of cirrhosis in these young patients may be related to multiple hepatic injuries induced by alcohol and parenteral heroin abuse and to the onset of addictive diseases during adolescence or early adult life.

Hepatic cirrhosis is infrequently diagnosed in young adults. ${ }^{1-5}$ In a hospital for addictive diseases in New York City, we found cirrhosis in 53 patients under age 35 within just 40 months. Although cirrhosis has been noted in unspecified numbers of substance abusers during adolescence ${ }^{6}$ and young adulthood, ${ }^{7}$ a detailed description of such patients has not been reported.

We report herein the clinical, biochemical, and pathological findings in these young patients. After several young adults with cirrhosis had been seen, we began a comparison of their HLA antigens with those of ethnically-matched controls with substance abuse but without liver disease. Other investigators have found associations between HLA antigens and alcoholic liver disease,${ }^{8}$ and in autoimmune chronic active hepatitis ${ }^{9}$ a particularly strong association with HLA antigens was found in the subset of patients with early onset of their disease.

Address for correspondence: Dr D M Novick. Beth Israel Medical Center, 10 Nathan D Perlman Place, New York, New York 10003, USA

Received for publication 26 March 1984

\section{Methods}

PATIENTS

All of the patients and controls in this study were admitted voluntarily to the Morris $\mathrm{J}$ Bernstein Institute of Beth Israel Medical Center, New York, USA, for treatment of substance abuse or medical complications thereof. This facility is several times larger than any other detoxification unit in New York City. From October 1978 to February 1982, a prospective study of chronic liver disease in drug and alcohol abusers of all ages was in progress. Two groups of patients are included in this report. Group I consists of all patients under age 35 who, during this 40 month period, had a liver biopsy which revealed cirrhosis. The liver biopsy was performed because of clinical indications in all patients, and no patient who underwent liver biopsy had a prior tissue diagnosis of cirrhosis. Group II consists of all patients under age 35 seen during a 13 month period ending 1 February 1982 in whom liver biopsy was contra-indicated and in whom cirrhosis was diagnosed clinically. This clinical diagnosis was 
based on the presence of chronic liver disease, a prothrombin time more than three seconds over control, either hypoalbuminaemia or spider angiomata, and one or more additional features of cirrhosis. $^{25}$ Without a tissue diagnosis, other forms of liver disease cannot be definitely excluded. Informed consent was obtained from all participants in this study.

Substance abuse histories (Table 1) were obtained at only two interviews during a single hospitalisation. Other sources of historical data were not used. Patient interviews were conducted by a physician and a physician assistant trained in substance abuse. The average daily consumption of ethanol during the month before admission was estimated. ${ }^{10}$ Alcohol abuse is defined as consumption of an amount equal to or greater than $113.4 \mathrm{~g} \mathrm{(4}$ oz) of pure ethanol either daily or in recurrent binges for one or more years. Three patients whose questionnaires indicated ingestion of lesser amounts but who had two or more hospitalisations for treatment of alcoholism were also considered to be alcohol abusers. Questions on past alcohol intake were focused on heavy consumption and not on social drinking.

The liver biopsies from group I patients were reviewed without knowledge of the clinical or laboratory data. Concomitant alcohol hepatitis,

Table 1 Substance abuse in young adults with cirrhosis

\begin{tabular}{|c|c|c|}
\hline & $\begin{array}{l}\text { Biopsy-proven } \\
\text { cirrhosis } \\
\text { (group I) }\end{array}$ & $\begin{array}{l}\text { Severe } \\
\text { cirrhosis } \\
\text { (group II) }\end{array}$ \\
\hline Patients (no) & 37 & 16 \\
\hline \multicolumn{3}{|l|}{ Alcohol abuse: } \\
\hline Current & 30 & 14 \\
\hline Former & 6 & 1 \\
\hline Never & 1 & 1 \\
\hline Age at onset $(\mathrm{yr})^{*}$ & $20 \cdot 2 \pm 0 \cdot 86$ & $21.5 \pm 0.76$ \\
\hline Duration (yr) & $8 \cdot 5 \pm 0 \cdot 80$ & $7 \cdot 6 \pm 1 \cdot 14$ \\
\hline $0-5 \mathrm{yr}$ & 11 & 5 \\
\hline $6-7 \mathrm{yr}$ & 4 & 4 \\
\hline $8-10 \mathrm{yr}$ & 12 & 3 \\
\hline $11-15 \mathrm{yr}$ & 7 & 3 \\
\hline $16-20 \mathrm{yr}$ & 3 & 1 \\
\hline \multicolumn{3}{|l|}{ Parenteral heroin abuse: } \\
\hline Current & 8 & 3 \\
\hline Former & $28+$ & 13 \\
\hline Never & 1 & 0 \\
\hline Heroin alone & 16 & 6 \\
\hline Heroin and cocaine & 20 & 10 \\
\hline Age at onset $(\mathrm{yr}) \ddagger$ & $16 \cdot 9 \pm 0.50$ & $15 \cdot 9 \pm 0 \cdot 61$ \\
\hline Duration (yr) & $6.9 \pm 0.68$ & $7.9 \pm 1.03$ \\
\hline Years since onset $\ddagger$ & $12 \cdot 5 \pm 0.52$ & $14 \cdot 3 \pm 0 \cdot 79$ \\
\hline
\end{tabular}

steatosis, and chronic active hepatitis were noted. ${ }^{11}$ All but four biopsy specimens were stained with periodic acid-Schiff (PAS) after diastase digestion, but phenotyping and immunoperoxidase stains specific for alpha $a_{1}$-antitrypsin were not performed. ${ }^{12}$

During the 40 month study period, a total of 204 patients of all ages who abused alcohol or parenteral substances underwent percutaneous liver biopsies because chronic liver disease was suspected. The non-cirrhotic patients under age 35 (Table 2) and the cirrhotic patients older than age 35 who are used in comparisons are from this larger series. To determine whether abuse of both alcohol and parenteral heroin contributed to early cirrhosis, we reviewed all patients under age 35 who had liver biopsies during the study period, and we compared the frequency of cirrhosis in abusers of alcohol only, parenteral heroin only, and both (Table 2). To determine whether early onset of substance abuse was related to early cirrhosis, we determined the correlation between age at onset of alcohol abuse and age at diagnosis of cirrhosis, and between age at onset of parenteral substance abuse and age at diagnosis of cirrhosis. For this analysis, the 86 patients of all ages who were found to have cirrhosis on liver biopsy during the study period were included.

\section{HLA STUDY}

HLA typing was performed in patients in groups I and II admitted to the hospital or seen in an affiliated outpatient clinic during 1981 and JanuaryApril, 1982. From the total of 53 patients, it was possible to obtain blood for HLA typing in 42 . HLA-DR antigens could not be discerned in one patient and three controls because of insufficient cells or technical problems.

The control group for the HLA study consists of 42 abusers of alcohol or parenteral heroin who were hospitalised for detoxification. All but three of the controls had abused both alcohol and parenteral heroin at some time, and the durations of alcohol

Table 2 Liver biopsy results in patients under age 35 with abuse of alcohol, parenteral heroin and both*

\begin{tabular}{llllll}
\hline $\begin{array}{l}\text { Liver biopsy } \\
\text { results }\end{array}$ & $\begin{array}{l}\text { Patients } \\
\text { (no) }\end{array}$ & $\begin{array}{l}\text { Alcohol } \\
\text { abuse } \\
\text { only } \dagger\end{array}$ & $\begin{array}{l}\text { Parenteral } \\
\text { heroin } \\
\text { only } \dagger\end{array}$ & $\begin{array}{l}\text { Alcohol and } \\
\text { parenteral } \\
\text { heroint }\end{array}$ & $\begin{array}{l}\text { Mean } \\
\text { age }\end{array}$ \\
\hline $\begin{array}{l}\text { Cirrhosis } \\
\text { Other }\end{array}$ & 37 & 1 & 1 & 35 & $29 \cdot 7 \pm 0.46$ \\
diagnoses & 65 & 5 & 22 & 38 & $29.2 \pm 0.46$ \\
\hline
\end{tabular}

* The patients represent 102 consecutive alcohol and/or parenteral heroin abusers under age 35 who underwent liver biopsy.

$\dagger$ Distributions are significantly different $(p<0 \cdot 001)$. 
and parenteral heroin abuse were similar in patients and controls. The controls were matched ethnically with the patients who had HLA typing within the following categories: black (16 patients), Hispanic (16 patients), white Italian-American (four patients), and white, other (six patients). None of the controls had evidence of liver disease on physical examination, and none had abnormal values for aspartate aminotransferase (AST), alanine aminotransferase (ALT), total bilirubin, alkaline phosphatase, total protein, or albumin. At least one hepatitis B marker was found in 41 of the 42 controls.

\section{ANALYTICAL METHODS}

Hepatitis B serologic tests, including hepatitis B surface antigen (HBsAg), antibody (anti-HBs), and antibody to the hepatitis B core antigen (anti-HBc), were performed by radioimmunoassay using commercially available kits (Abbott Laboratories, North Chicago, Illinois, USA).

HLA typing for A, B, and C specificities was performed by a microlymphocytotoxicity technique $^{13}$ using a panel of 120 antisera. For DR typing, B lymphocytes were isolated using nylon wool columns, ${ }^{14}$ and a microlymphocytotoxicity method with prolonged incubation times was used. A panel of 60 antisera was used for DR typing. We assessed 16 antigens at the $A$ locus, 33 at the $B$ locus, eight at the $C$ locus, and nine at the DR locus. The nomenclature is that of the Eighth International Histocompatibility Workshop. ${ }^{14}$

\section{STATISTICS}

Results are expressed as mean \pm SEM. The method of $\chi^{2}$ was used for comparisons. Yates' correction was applied to all two by two $\chi^{2}$ tables including those for the HLA study. The $p$ values obtained in the HLA study were multiplied by 66 , the total number of HLA antigens tested. ${ }^{15}$

\section{Results}

Hepatic cirrhosis was diagnosed between ages 24 and 34 years in the 53 patients, with a mean age at diagnosis of $29 \cdot 8 \pm 0 \cdot 39$ years. The Figure shows the age distribution. Thirty nine cirrhotic patients were men $(74 \%)$, and 14 were women $(26 \%)$. None of the men was homosexual. Nineteen patients $(36 \%)$ had evidence of decompensated liver disease as manifested by jaundice, ascites, or encephalopathy. The mean AST was $152 \pm 12 \cdot 7$, more than twice the value for the mean ALT, ${ }^{16}$ which was $72 \pm 7 \cdot 2$. Five of the 53 patients $(9.4 \%)$ were HBsAg carriers, and 44 of 47 tested $(93.6 \%)$ had at least one positive hepatitis $B$ marker.
The substance abuse (Table 1) consisted of alcohol abuse in 51 patients $(96 \%)$ and parenteral heroin abuse, with or without parenteral cocaine, in $52(98 \%)$. All but three patients $(94 \%)$ had a history of current or previous abuse of both alcohol and parenteral heroin. Alcohol abuse began at ages 12-32 years (Figure), with a mean age of onset of $20.6 \pm 0.65$ years. The mean duration of alcohol abuse before diagnosis of cirrhosis was $8 \cdot 2 \pm 0.65$ years, and it was present for seven or fewer years in 24 patients $(45 \%)$ and 10 or fewer in 39 patients (74\%). Use of lesser amounts of alcohol must have preceded alcohol abuse as defined. Parenteral heroin abuse began at ages 12-25 years (Figure), with a mean age of onset of $16 \cdot 6 \pm 0.39$ years. It began $13 \cdot 1 \pm 0 \cdot 45$ years before the diagnosis of cirrhosis, and its mean duration was $7 \cdot 2 \pm 0 \cdot 57$ years. Parenteral heroin abuse began before age 20 in 44 patients $(83 \%)$, and both alcohol abuse and parenteral heroin abuse began before age 20 in 22 patients $(42 \%)$.

Review of the 37 liver biopsies from the group I patients disclosed micronodular cirrhosis in 27 (73\%). Macronodular cirrhosis was seen in one patient, mixed micro- and macronodular cirrhosis in six, and incomplete septal cirrhosis in three. In addition to the cirrhosis, nine patients had alcohol hepatitis, six had severe steatosis, and 12 had

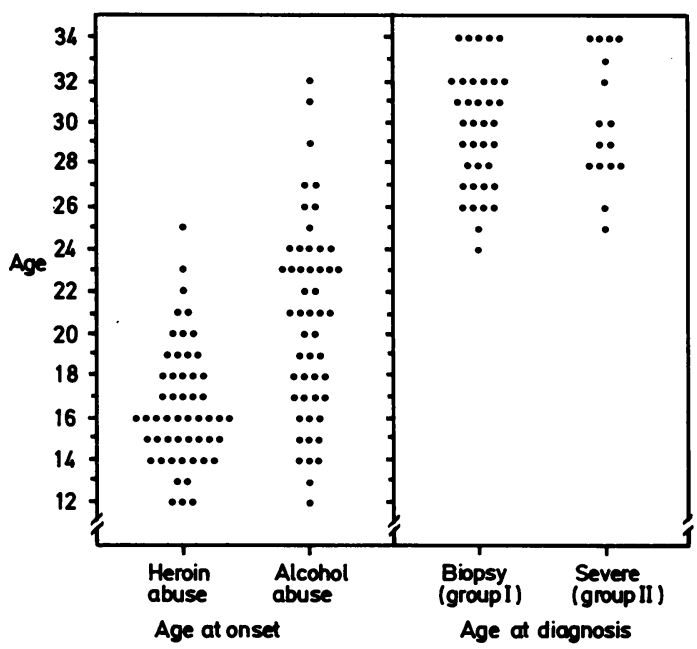

Figure Age distributions for the onset of parenteral heroin abuse and alcohol abuse (as defined in text) and for the diagnosis of cirrhosis either by liver biopsy (group I) or by clinical means (group II). Patients in group II had liver disease of such severity that liver biopsy was contraindicated. 
chronic active hepatitis. Five of 33 patients $(15 \%)$ had PAS-positive diastase-resistant inclusions consistent with alpha ${ }_{1}$-antitrypsin.

During the 40 month period of this study, cirrhosis was found on liver biopsy in $86(42 \%)$ of 204 patients of all ages who abused alcohol, parenteral substances, or both. Seventeen of the 86 (20\%) with cirrhosis were under age 30 , and 37 (43\%) were under age 35 . There were 147 patients of all ages who abused both alcohol and parenteral substances at some time. In this group, cirrhosis was found in 35 of $73(48 \%)$ patients under age 35 and in 41 of $74(55 \%)$ patients age 35 or older. When all 86 patients with cirrhosis at any age were considered, significant correlations were found between age of onset of parenteral substance abuse and age at diagnosis $(r=0.539 ; p<0.001)$, and between the age of onset of alcohol abuse and age at diagnosis $(\mathrm{r}=0.519 ; \mathrm{p}<0.001)$.

Table 2 relates the type of substance abuse to the presence or absence of cirrhosis in 102 consecutive patients under age 35 who underwent liver biopsy. A comparison of subgroups who abused alcohol only, parenteral heroin only, or both revealed that cirrhosis was significantly more frequent in abusers of both alcohol and parenteral heroin $(p<0.001)$.

The distributions of the 66 HLA antigens did not differ $(p \times 66>0.05)$ between patients and controls (Table 3). The HLA antigens in subgroups of patients (group II, age under 30 , ascites) were also similar to those in the controls.

\section{Discussion}

In five series of unselected patients with cirrhosis from five different countries, ${ }^{1-5}$ the peak incidence was in the fifth or sixth decades and the percentage of patients under age 30 ranged from $0.5-5.4 \%$. Alcohol abuse was an aetiologic factor in $14-50 \%$ of the patients in these series. Alcoholic cirrhosis has been infrequently reported in young adults. ${ }^{17}{ }^{18}$ Our findings that $20 \%$ of 86 biopsied patients who had cirrhosis were under 30 , and that $43 \%$ were under 35 , contrast greatly with these studies. These differences must be interpreted cautiously in view of the relatively young population served by our institution. The median age of 2106 consecutive admissions was 32 years; $36.5 \%$ were under age 30 , and $60.6 \%$ were under age 35 . We hypothesise that older patients are not seen at this institution because either their substance abuse is being successfully treated or they have died of medical complications. ${ }^{19}$

An evaluation of $66 \mathrm{HLA}$ antigens from the A, B, $C$, and DR loci in 42 patients and controls failed to reveal a significant association between any HLA
Table 3 Frequency and (percentage) of HLA antigens*

\begin{tabular}{lll}
\hline HLA antigen & $\begin{array}{l}\text { Patients } \\
(n=42)\end{array}$ & $\begin{array}{l}\text { Controls } \\
(n=42)\end{array}$ \\
\hline Aw31 & $3(7 \cdot 1)$ & 0 \\
B8 & $5(11 \cdot 9)$ & $5(11 \cdot 9)$ \\
B13 & $3(7 \cdot 1)$ & $2(4 \cdot 8)$ \\
Bw51 (5) $\dagger$ & $8(19 \cdot 0)$ & 0 \\
Bw60 $(40)$ & $1(2 \cdot 4)$ & $7(16 \cdot 7)$ \\
Bw61 (40) & $1(2 \cdot 4)$ & $1(2 \cdot 4)$ \\
Cw3 & $6(14 \cdot 3)$ & $8(19 \cdot 0)$ \\
Cw4 & $7(16 \cdot 7)$ & $15(35 \cdot 7)$ \\
DR1 $\ddagger$ & $7(17 \cdot 1)$ & $3(7 \cdot 7)$ \\
DR2 & $7(17 \cdot 1)$ & $4(10 \cdot 3)$ \\
DR3 & $9(22 \cdot 0)$ & $8(20 \cdot 5)$ \\
\hline
\end{tabular}

* No significant differences between the distributions of 66 HLA antigens in patients and controls were found. The HLA antigens shown here are those with the highest Yates' corrected $\chi^{2}$ values in each locus as well as those which have had significant associations with chronic liver disease in other studies. ${ }^{892122}$ The data for all 66 HLA antigens may be obtained from the corresponding author. † In instances where broad HLA specificities have been split into narrow specificities, the narrow specificities are shown followed by the original broad specificity in parentheses.

¥ HLA-DR typing was performed in 41 patients and 39 controls.

antigen and cirrhosis (Table 3). A drawback to our HLA study is the heterogeneity of ethnic backgrounds of the cirrhotic patients, but the ethnic matching of the control substance abusers should correct for this. A type II error (failure to find a significant association when one exists, because of an insufficiently large number of patients studied) might have occurred, ${ }^{20}$ but none of the HLA comparisons were even close to statistical significance. Other studies of HLA antigens in alcoholic liver disease have been conflicting. 82122

Cirrhosis can develop in patients with homozygous or heterozygous alpha ${ }_{1}$-antitrypsin deficiency. ${ }^{12}$ In our study, five of $33(15 \%)$ patients had diastase-resistant PAS-positive inclusions characteristic of alpha ${ }_{1}$-antitrypsin. The presence of these lesions is not specific for alpha ${ }_{1}$-antitrypsin, and they have been observed in the hepatocytes of patients with alcoholic cirrhosis in the absence of alpha $_{1}$-antitrypsin deficiency. ${ }^{23}$ As immunoperoxidase stains and phenotyping were not performed, it is uncertain whether any of the five patients with inclusions had alpha ${ }_{1}$-antitrypsin deficiency.

The most important factors leading to cirrhosis in our patients appear to be related to their substance abuse. All patients abused alcohol or parenteral heroin, and 50 of $53(94 \%)$ abused both. Alcohol is a well-known cause of cirrhosis. Parenteral heroin abuse leads to chronic liver disease by inoculation of hepatitis $B^{24}{ }^{25}$ and non-A, non-B viruse ${ }^{26}$ and the 
delta agent. ${ }^{27}$ Although infection with these agents may lead to cirrhosis, previous series of liver biopsies in parenteral substance abusers disclosed few $^{28}$ or no ${ }^{29-31}$ patients with cirrhosis. Chronic active hepatitis, chronic persistent hepatitis, and non-specific reactive hepatitis were the most common lesions. Most parenteral substance abusers with cirrhosis have also been alcohol abusers. ${ }^{24} 32$

The observations that cirrhosis is infrequent in young alcohol abusers as well as in non-alcoholic parenteral substance abusers have led to the hypothesis that abuse of both alcohol and parenteral substances accelerates the development of cirrhosis. Our finding in a series of 102 consecutive substance abusers under age 35 who underwent liver biopsy (Table 2) that cirrhosis was significantly associated with abuse of both alcohol and parenteral heroin appears to support this hypothesis. The relatively short duration of alcohol abuse in many of our patients also suggests that multiple factors contributed to the cirrhosis. For example, alcohol abuse had occurred for seven or fewer years before the diagnosis of cirrhosis in 24 patients $(45 \%)$ and for 10 or fewer years in $39(74 \%)$. In a study of 334 alcohol abusers who consumed at least $130 \mathrm{~g}$ of ethanol per day, ${ }^{33}$ Lelbach found cirrhosis in only $8 \%$ of those drinking for 10 or fewer years.

Parenteral heroin abuse, with or without alcohol abuse, began in adolescence in $44(83 \%)$ of the young adults with cirrhosis. We found that the age of onset of alcohol abuse and the age of onset of parenteral substance abuse were each significantly correlated with the age at diagnosis of cirrhosis. Cirrhosis was found in similar percentages of combined alcohol and parenteral substance abusers above $(55 \%)$ and below (48\%) age 35 . These data suggest that the earlier substance abuse commences, the earlier cirrhosis will be seen. Our study therefore lends support to the concept that efforts to prevent substance abuse should begin during childhood. ${ }^{34}$

The finding of more than one type of substance abuse in $94 \%$ of our patients with cirrhosis suggests that programmes devoted to one type should not be oblivious or antagonistic to patients with multiple addictions. For example, methadone maintenance patients who attend alcohol programmes should not be counselled to discontinue methadone treatment,$^{35}$ as is often the case. Similarly, the drug free or methadone maintenance programme may be a point of entry into alcohol treatment, because alcohol abuse does not preclude successful participation in methadone maintenance. ${ }^{36}$ Prevention of alcohol and parenteral drug abuse should help to prevent or delay the onset of cirrhosis, which cannot be cured once established.
The authors thank $R \mathrm{~J}$ Winchester and $\mathrm{R} G$ Newman for expert scientific assistance, $J$ Most for data tabulation and statistical analysis, M S Rubenstein for providing Bernstein Institute admissions data, and J G P Novick and F Raysor for editorial and secretarial assistance. Dr Kreek is the recipient of a Research Scientist Award from ADAMHA-NIDA (DA-00049) and Grant No. C148038 from the New York State Office of Drug Abuse Services. An abstract of this work was published in Hepatology 1982; 2: 675.

\section{References}

1 Hällén J, Linné I. Cirrhosis of the liver in one community. A study of 768 cases of liver cirrhosis from a city with one hospital: incidence, etiology, and prognosis. In: Engel E, Larsson T, eds. Alcoholic cirrhosis and other toxic hepatopathies. Stockholm: Nordiska Bokhandelns Forlag, 1970: 336-55.

2 Yoshida T, Kawata H, Fukui O, Koizumi T, Asada M, Wada M. Cirrhosis of the liver in Japan. Acta HepatoSplenol 1965; 12: 268-78.

3 Stone WD, Islam NRK, Paton A. The natural history of cirrhosis. Experience with an unselected group of patients. $Q J$ Med 1968; 37: 119-32.

4 Creutzfeldt W, Beck K. Cirrhosis of the liver. On the aetology, pathogenesis, results of treatment and period of survival in an unselected series of 560 patients. Germ Med Mth 1966; 11: 259-65.

5 Henrikson EC. Cirrhosis of the liver with special reference to the surgical aspects. Arch Surg 1936; 32: 413-51.

6 Litt IF, Cohen MI, Schonberg SK, Spigland I. Liver disease in the drug-using adolescent. J Pediatr 1972; 81: 238-42.

7 Sapria JD, Cherubin CE. Drug abuse: a guide for the clinician. Amsterdam: Experta Medica, 1975: 93-4.

8 Eddleston ALWF, Davis M. Histocompatibility antigens in alcoholic liver disease. Br Med Bull 1982; 38: $13-6$.

9 Mackay IR, Tait BD. HLA associations with autoimmune-type chronic active hepatitis: identification of B8-DRw3 haplotype by family studies. Gastroenterology 1980; 79: 95-8.

10 Gelb AM, Richman BL, Anand OP. Quantitative and temporal relationships of alcohol use in narcotic addicts and methadone maintenance patients undergoing alcohol detoxification. Am J Drug Alcohol Abuse 1978; 5: 191-8.

11 International Group. Acute and chronic hepatitis revisited. Lancet 1977; 2: 914-9.

12 Hodges JR, Millward-Sadler GH, Barbatis C, Wright $R$. Heterozygous $M Z$ alpha $_{1}$-antitrypsin deficiency in adults with chronic active hepatitis and cryptogenic cirrhosis. N Engl J Med 1981; 304: 557-60. 
13 Teresaki PI, Bernoco D, Park MS, Ozturk G, Iwaki Y. Microdroplet testing for HLA-A, -B, -C, and -D antigens. Am J Clin Pathol 1978; 69: 103-20.

14 Danilovs JA, Ayoub G, Terasaki PI. B lymphocyte isolation by thrombin-nylon wool. In: Terasaki PI, ed. Histocompatibility testing 1980. Los Angeles: UCLA Tissue Typing Laboratory, 1980; 287-8.

15 Svejgaard A, Jersild C, Staub Nielsen L, Bodmer WF. HL-A antigens and disease: Statistical and genetical considerations. Tissue Antigens 1974; 4: 95-105.

16 Cohen JA, Kaplan MM. The SGOT/SGPT ratio - an indicator of alcohol liver disease. Dig Dis Sci 1979; 24: 835-8.

17 Kramer K, Kuller L, Fisher R. The increasing mortality attributed to cirrhosis and fatty liver, in Baltimore (1957-1966). Ann Intern Med 1968; 69: 273-82.

18 Schuckit MA, Gunderson EKE. Deaths among young alcoholics in the U.S. Naval Service. $Q J$ Stud Alcohol 1974; 35: 856-62.

19 Concool B, Smith H, Stimmel B. Mortality rates of persons entering methadone maintenance: a seven-year study. Am J Drug Alcohol Abuse 1979; 6: 345-53.

20 Freiman JA, Chalmers TC, Smith H, Kuebler RR. The importance of beta, the type II error and sample size in the design and interpretation of the randomized control trial. N Engl J Med 1978; 299: 690-4.

21 Shigeta $\mathrm{Y}$, Ishii $\mathrm{H}$, Takagi S, et al. HLA antigens as immunogenetic markers of alcoholism and alcoholic liver disease. Pharmacol Biochem Behav 1980; 13: suppl 1: 89-94.

22 Tait BD, Mackay IR. HLA and alcoholic cirrhosis. Tissue Antigens 1982; 19: 6-10.

23 Pariente EA, Degott C, Martin JP, Feldman G, Potet F, Benhamou JP. Hepatocytic PAS-positive diastaseresistant inclusions in the absence of alpha ${ }_{1}$-antitrypsin deficiency - High prevalance in alcoholic cirrhosis. $\mathrm{Am}$ J Clin Pathol 1981; 76: 299-302.

24 Novick DM, Gelb AM, Stenger RJ, et al. Hepatitis B serologic studies in narcotic users with chronic liver disease. Am J Gastroenterol 1981; 75: 111-5.

25 Kreek MJ, Dodes L, Kane S, Knobler J, Martin R.
Long-term methadone maintenance therapy: Effects on liver function. Ann Intern Med 1972; 77: 598-602.

26 Dienstag JL, Stevens CE, Szmuness W. The epidemiology of non-A, non-B hepatitis: Emerging patterns. In Gerety RJ, ed. Non- $A$, non- $B$ hepatitis. New York: Academic Press, 1981; 119-38.

27 Rizzetto M. The delta agent. Hepatology 1983; 3: 729-37.

28 Seeff LB, Zimmerman HJ, Wright EC, et al. Hepatic disease in asymptomatic parenteral narcotic drug abusers: a Veterans Administration collaborative study. Am J Med Sci 1975; 270: 41-47.

29 Cherubin CE, Rosenthal WS, Stenger RE, et al. Chronic liver disease in asymptomatic narcotic addicts. Ann Intern Med 1972; 76: 391-95.

30 Ireton HJC, Gust ID, Moon WJ, Lehmann N, Stening GF, Smallwood RA. The covert liver disease of drug addicts. Aust NZ J Med 1974; 4: 444-9.

31 Cherubin CE, Schaefer RA, Rosenthal WS, et al. The natural history of liver disease in former drug users. Am J Med Sci 1976; 272: 244-53.

32 Sapira JD, Ball JC, Penn H. Causes of death among institutionalized narcotic addicts. J Chronic Dis 1970; 22: 733-42.

33 Lelbach WK. Quantitative aspects of drinking in alcoholic liver cirrhosis. In: Khanna JM, Israel Y, Kalant $\mathrm{H}$, eds. Alcoholic liver pathology. Toronto: Alcoholism and Drug Addiction Research Foundation of Ontario, Canada, 1975; 1-18.

34 Christiansen BA, Goldman MS, Inn A. Development of alcohol-related expectancies in adolescents: Separating pharmacological from social-learning influences. J Consult Clin Psychol 1982; 50: 336-44.

35 Stimmel B, Cohen M, Hanbury R. Alcoholism and polydrug abuse in persons on methadone maintenance. Ann NY Acad Sci 1978; 311: 99-109.

36 Hartman N, Kreek MJ, Ross A, Khuri E, Millman RB, Rodriguez $R$. Alcohol use in youthful methadone maintained former heroin addicts: liver impairment and treatment outcome. Alcoholism (NY) 1983; 7: 316-20. 